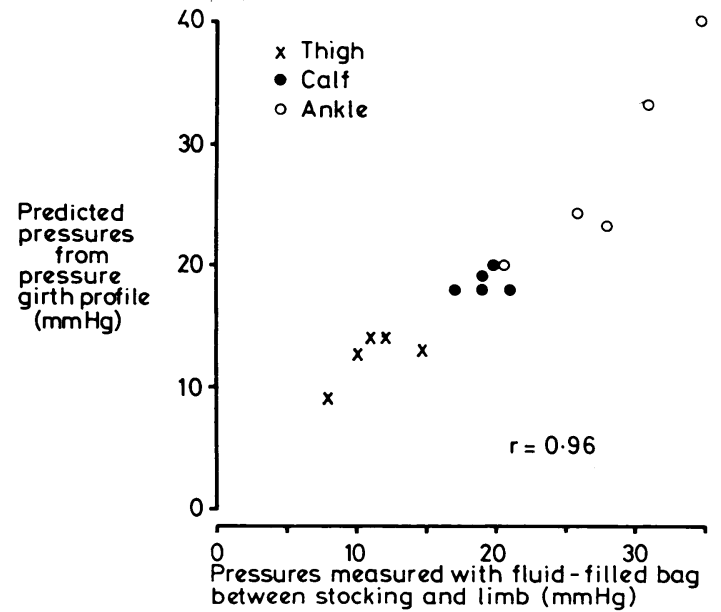

FIG 5-Correlation between predicted pressures from pressure-girth profile and pressures measured with fluidfilled bag between stockings and limb. Results are from five stockings of different size applied on the same limb.

will be for any limb. Only three simple measurements need be made of these sites using a tape measure. We have also shown the accuracy of the prediction

Possible applications for the method include quality control. During manufacture, for example, the pressure-girth profiles of batches of stockings may be measured to ensure the correct compression, and the method's use for a hysteresis test will indicate the quality of rubber used in knitting. Retesting stocking compression at intervals during routine use will show how they withstand washing and wearing and allow inferior brands to be identified. The pressure gauge may also be calibrated to give a direct reading on to a stocking-making machine, so that exact specifications of stockings can be made by the pressure readings from a standard stocking.

The most promising clinical application, however, will be to determine whether the pressure exerted by a stocking when applied on a particular limb will be graduated-that is, higher in the ankle than in the calf and thigh. The beneficial effect of stockings that produce a graduated compression on the leg has been already shown, ${ }^{2-5}$ and use of the new method will ensure that patients are fitted with such stockings (see accompanying paper).

\section{References}

${ }^{1}$ Heywood JJ. Notes on elastic hosiery. Retail Chemist 1972 Mar 30.

${ }^{2}$ Holford CP. Graded compression for preventing deep venous thrombosis. Br Med F 1976;ii:969-70.

${ }^{3}$ Sigel B, Edelstein AL, Felix WR, Memhardt CR. Compression of the deep venous system of the lower leg during inactive recumbency. Arch Surg 1973;106:38-43.

4 Sommerville JJ, Byrne PH, Fegan WG. Evaluation of elastic stockings in venous insufficiency. Br F Surg 1973;60:908.

5 Sigel B, Edelstein AL, Savitch L, Hasty JH, Felix WR. Type of compression for reducing venous stasis. A study of lower extremities during inactive recumbency. Arch Surg 1975;110:171-5.

- Sigg K. Die Kompression mit verbänden und gummistrümpfen zur prophylaxe und therapie venöser beinleiden. Forschritte der Medizin 1963;81:601.

7 Fentem PH, Goddard M, Gooden BA. Support for varicose veins. Br Med F 1976; : 254-6.

${ }^{8}$ Makin GS, Mayes FB, Holroyd AM. Studies on the effect of "tubigrip" on flow in the deep veins of the calf. Br F Surg 1969;56:369-72.

\title{
Value of graduated compression stockings in deep venous insufficiency
}

\author{
J HORNER, J FERNANDES É FERNANDES, A N NICOLAIDES
}

\section{Summary and conclusions}

The effect of elastic stockings on ambulatory venous pressure was investigated in $22 \mathrm{limbs}$ with deep venous insufficiency. The failure of some elastic stockings to reduce the ambulatory venous pressure in some limbs is due to the lack of graduated compression, which is caused by ankle-calf disproportion-narrow ankles and wide calves. This can be recognised by using the pressure-girth profile and corrected by specially made stockings with increased tension at the ankle. A pressure-girth profile established for each stocking enabled the exact compression exerted by the stocking along the length of each limb to be determined.

Elastic stockings exerting a graduated compression between ankle and calf induced a reduction in the ambulatory venous pressure in all but one limb. The greater

Academic Surgical Unit and Vascular Laboratory, St Mary's Hospital Medical School, London

J HORNER, FSC(SA), FRCSED, senior surgical registrar

J FERNANDES É FERNANDES, MD, research fellow and honorary senior registrar

A N NICOLAIDES, MS, FRCS, senior lecturer in cardiovascular surgery, director of clinical vascular laboratory the degree of graduated compression between ankle and calf exerted by the stocking, the greater the fall in ambulatory venous pressure. This may explain the beneficial effect of compression in limbs with venous ulceration.

\section{Introduction.}

The prescription of elastic stockings is the most common treatment for deep venous insufficiency, yet some patients refuse to wear them because the stockings fail to relieve their symptoms or make them worse. Elastic stockings that provide a graduated compression have been shown to reduce the ambulatory venous pressure and are therefore the stockings of choice. ${ }^{1}$

The circumferential pressure exerted on a limb by a stocking depends both on the limb circumference at different levels and the circumferential tension of the stockings at each level. It is thus incorrect to label a specific stocking as "graduated" until it has been individually matched to a patient's limb. The same stocking may exert graduated compression on one limb but not on another of different dimensions. This lack of graduated compression may be the cause of its failure to reduce the ambulatory venous pressure and relieve symptoms.

We therefore studied the effects of elastic stockings on the ambulatory venous pressure of patients with deep venous insufficiency. A brand of stockings commonly available in the 
National Health Service was used to determine: (a) whether graduated compression could be achieved on every limb by available stockings; $(b)$ the compression that produced the greatest reduction in the ambulatory venous pressure; and (c) the significance of the pressure gradient between ankle and calf produced by the stocking.

\section{Methods}

Twenty-two limbs (18 patients) with deep venous insufficiency were studied. All limbs had been investigated by directional Doppler ultrasound (Parks model 806) and by venography. The criterion for including the patients in the study was the presence of deep venous insufficiency as indicated by reflux in the popliteal vein, detected with directional Doppler ultrasound, and an abnormally high ambulatory venous pressure $(50-100 \mathrm{~mm} \mathrm{Hg}$ ) even when the superficial veins were compressed or occluded by a pressure cuff. The presence or absence of deep venous occlusion was determined by venography. It was present in three patients (four limbs) who had a history of venous claudication. One of these patients had previously undergone a vein patch to his internal iliac vein to restore patency.

Elastic stockings-Toeless Softgrip elastic stockings (Scholl UK) were selected because they are commonly prescribed and have a range of four sizes. A second range of stockings with increased ankle tension was specifically manufactured for the study.

Pressure grading of elastic stockings-For each size of stocking graphs of pressure against circumference were obtained for ankle and calf, using the device described in the preceding paper. Profiles were obtained for all the stockings used in the study.

Measurement of ambulatory venous pressure-A 21-G (bore 20-G) butterfly needle was inserted into a vein on the dorsum of the foot and connected through an Akers transducer (model 840) and BAP 001 amplifier to a potentiometric pen recorder (J \& J Instruments, model

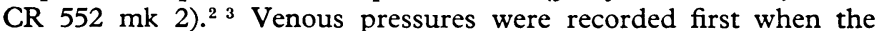
patient stood still and then when he walked on the spot at 100 steps per minute. Pressure tracings were recorded with and without a 2.5$\mathrm{cm}$ wide ankle cuff inflated to $120 \mathrm{~mm} \mathrm{Hg}$ to exclude the superficial system of veins. ${ }^{3}$ Venographic studies have shown that such a cuff does not affect the deep veins. ${ }^{4}$

The stockings to be tested were slipped over the needle and on to the leg by means of a Tubigrip applicator. Two stockings were tested on each limb, each producing a different gradient between ankle and calf.

\section{Results}

The range of standard Softgrip stockings could not provide a graduated pressure for four limbs with narrow ankles and large calves which fell outside the standard chart (limb size to stocking size) provided by the manufacturers. However, by using the specially manufactured stockings with increased strength at the ankle, it became possible to provide all limbs with graduated compression stockings.

When the patients were standing still the venous pressure ranged from 80 to $90 \mathrm{~mm} \mathrm{Hg}$. This corresponded to the hydrostatic pressure exerted by a column of blood from the ankle to the level of the right atrium. ${ }^{5}$ Elastic stockings had no effect on these pressures.

The ambulatory venous pressures without and with the stockings are shown in table 1. They indicate that the greater the compression gradient between ankle and calf produced by the stocking, the lower the ambulatory venous pressure.

Stockings exerting a graduated pressure lowered the ambulatory venous pressure in all but two limbs with hypertension due to deep venous occlusion (limbs 21 and 22).

\section{Discussion}

Our findings suggest that, although the majority of limbs can be provided with graduated compression from the available range of standard stockings, this is not possible in the presence of calf-ankle disproportion-that is, narrow ankles with large calves. This significant minority of patients may, when recognised, have the appropriate stockings prescribed. The tourniquet effect at calf level, which traps blood in the distal veins, may thus be avoided. Stockings producing higher compression in the calf
Ambulatory venous pressure $(A V P)$ and compression gradient in each limb produced by two elastic stockings, one of which exerted higher differential compression than the other

\begin{tabular}{|c|c|c|c|c|c|}
\hline \multirow[b]{2}{*}{ Limb No } & \multirow[b]{2}{*}{$\begin{array}{l}\text { AVP without } \\
\text { stockings } \\
\text { (mm Hg) }\end{array}$} & \multicolumn{2}{|c|}{$\begin{array}{l}\text { Stockings with higher } \\
\text { differential compression }\end{array}$} & \multicolumn{2}{|c|}{$\begin{array}{l}\text { Stockings with lower } \\
\text { differential compression }\end{array}$} \\
\hline & & $\underset{(\mathrm{mm} \mathrm{Hg})}{\mathrm{AVP}^{*}}$ & $\begin{array}{l}\text { Compression } \\
\text { gradient in } \\
(\mathrm{mm} \mathrm{Hg})\end{array}$ & $\underset{(\mathrm{mm} \mathbf{H g})}{\mathbf{A V P}}$ & $\begin{array}{l}\text { Compression } \\
\text { gradient in } \\
(\mathrm{mm} \mathrm{Hg})\end{array}$ \\
\hline $\begin{array}{r}1 \\
2 \\
3 \\
4 \\
5 \\
6 \\
7 \\
8 \\
9 \\
10 \\
11 \\
12 \\
13 \\
14 \\
15 \\
16 \\
17 \\
18 \\
19 \\
20 \\
21 \\
22\end{array}$ & $\begin{array}{r}100 \\
95 \\
100 \\
70 \\
100 \\
75 \\
75 \\
80 \\
85 \\
100 \\
100 \\
70 \\
90 \\
90 \\
75 \\
80 \\
80 \\
90 \\
105 \\
145 \\
160 \\
110\end{array}$ & $\begin{array}{r}70 \\
50 \\
75 \\
45 \\
85 \\
45 \\
45 \\
45 \\
65 \\
80 \\
75 \\
50 \\
70 \\
40 \\
40 \\
80 \\
50 \\
70 \\
65 \\
120 \\
160 \\
160\end{array}$ & $\begin{array}{l}-17 \\
-18 \\
-5 \\
-8 \\
-9 \\
-17 \\
-17 \\
-14 \\
-16 \\
-7 \\
-21 \\
-20 \\
-15 \\
-16 \\
-11 \\
-2 \\
-4 \\
-4 \\
-22 \\
-24 \\
-17 \\
-17\end{array}$ & $\begin{array}{r}70 \\
65 \\
80 \\
50 \\
80 \\
50 \\
70 \\
70 \\
75 \\
75 \\
70 \\
70 \\
60 \\
55 \\
70 \\
95 \\
80 \\
95 \\
85 \\
140 \\
160 \\
160\end{array}$ & $\begin{array}{l}-13 \\
-8 \\
-4 \\
-8 \\
-3 \\
-12 \\
-11 \\
-10 \\
-7 \\
-4 \\
-12 \\
-5 \\
-12 \\
-4 \\
-4 \\
0 \\
+4 \dagger \\
+10 \dagger \\
-7 \pm \\
-9 \pm \\
-2 \ddagger \\
-13 \ddagger\end{array}$ \\
\hline
\end{tabular}

*Difference in AVP between the two stockings (Wilcoxon matched pairs signed-ranks test) $=p<0.01$ (limbs 17 and 18 were excluded because compression gradient was not achieved. When included statistical significance was greater).

tGraded compression not achieved.

$\ddagger$ Limbs with deep venous obstruction.

than in the ankle did not lower the ambulatory venous pressure (see table; limbs 17 and 18), but stockings with a greater compression at the ankle than at the calf reduced the ambulatory venous pressure.

The therapeutic effect of elastic stockings on the incidence of ulceration may be related to the ambulatory venous pressure. Shull et al found that in limbs with ambulatory venous pressures greater than $60 \mathrm{~mm} \mathrm{Hg}$ the incidence of ulceration was $66 \%$, in those with pressures of 40 to $60 \mathrm{~mm} \mathrm{Hg}$ it was $26 \%$, and in those with pressures less than $40 \mathrm{~mm} \mathrm{Hg}$ it was zero. ${ }^{5}$ Our results indicate that graduated compression can reduce the ambulatory venous pressure by as much as 20 to $30 \mathrm{~mm} \mathrm{Hg}$. This may explain one mechanism of the beneficial effect of elastic stockings. Nevertheless, such benefit can occur only if graduated compression is produced, and the latter can be ensured only by using a method that can determine the individual requirement for a particular limb. The method of determining the pressure-girth profile of a stocking described in the previous paper is a simple way of achieving this. We hope that eventually the pressure profile of all brands of stockings will become available and supplied with each pair. Thus the potentially harmful effects and waste of funds associated with the incorrect prescription of elastic stockings may be prevented.

We thank Professor H A F Dudley and Mr J T Hobbs for their encouragement and support and for allowing us to study their patients; Scholl (UK) for supplying elastic stockings, and Scholl Foundation for a research fellowship to J Horner.

\section{References}

${ }^{1}$ Sommerville JJ, Byrne PH, Fegan WG. Analysis of flow patterns in venous insufficiency. Br $\mathcal{F}$ Surg $1974 ; 61: 40-4$.

2 Fernandes é Fernandes J, Shull K, Horner J, Hobbs JT, Needham TN, Nicolaides AN. The significance of the popliteal valve in relation to ambulatory venous pressure and ulceration. Br f Surg 1979;66:369.

${ }^{3}$ Lewis JD, Parsons DCS, Needham TN, et al. The use of venous pressure measurements and directional doppler recordings in distinguishing between superficial and deep valvular incompetence in patients with deep venous insufficiency. Br F Surg 1973;60:312.

4 Nicolaides AN, Kakkar VV, Field ES, Renney JTG. The origin of deep vein thrombosis: a venographic study. $B r \mathcal{F}$ Radiol 1971 ;44:653-63.

5 Shull KC, Nicolaides AN, Fernandes é Fernandes J, et al. Significance of popliteal reflux in relation to ambulatory venous pressure and ulceration. Arch Surg 1979;114:1304-6. 